\title{
Inhibition of the signal transducer and activator of transcription 3 signaling pathway by Qianliening capsules suppresses the growth and induces the apoptosis of human prostate cells
}

\author{
JIUMAO LIN ${ }^{1,2}$, JIANHENG ZHOU ${ }^{3}$, XIAOYONG ZHONG ${ }^{1}$, ZHENFENG HONG $^{1,2}$ and JUN PENG ${ }^{1,2}$ \\ ${ }^{1}$ Academy of Integrative Medicine Biomedical Research Center, ${ }^{2}$ Fujian Key Laboratory of Integrative Medicine on Geriatrics, \\ ${ }^{3}$ Department of Integrative Medicine, Fujian University of Traditional Chinese Medicine, Fuzhou, Fujian 350122, P.R. China
}

Received January 9, 2014; Accepted October 31, 2014

DOI: $10.3892 / \mathrm{mmr} .2014 .2946$

\begin{abstract}
The signal transducer and activator of transcription 3 (STAT3) pathway is one of the main growth factor-mediated signal transduction pathways and is closely associated with the occurrence and development of benign prostatic hyperplasia (BPH). Qianliening capsules (QC) have significant therapeutic effects on BPH; however, the precise mechanism underlying its anti-BPH activity remains to be elucidated. To further elucidate the molecular mechanism of the therapeutic effect of QC on $\mathrm{BPH}$, the present study used epidermal growth factor (EGF), which has a role in the pathogenesis of $\mathrm{BPH}$, to stimulate the growth of human prostate WPMY-1 cells and activate the STAT3 pathway in the WPMY-1 cells. The cell viability was determined using an MTT assay and the cell morphology was observed by phase-contrast microscopy. Fluorescence activated cell sorting analysis with Annexin-V/propidium iodide (PI) staining and PI staining were performed to examine cell apoptosis and the cell cycle. The activation of caspase- 9 and -3 were evaluated by colorimetric assay. STAT3 phosphorylation and transcriptional activity were detected by western blot analysis and the luciferase gene reporter, respectively. The mRNA and protein expression levels of B-cell lymhoma 2 (Bcl-2), Bcl-2-associated X protein (Bax), cyclin D1, cyclin-dependent kinase 4 (CDK4) and p21 were measured by reverse transcription quantitative polymerase chain reaction
\end{abstract}

Correspondence to: Professor Zhenfeng Hong or Dr Jun Peng, Academy of Integrative Medicine Biomedical Research Center, Fujian University of Traditional Chinese Medicine, 1 Qiuyang Road, Minhou Shangjie, Fuzhou, Fujian 350122, P.R. China

E-mail: zfhong1953@163.com

E-mail: pjunlab@hotmail.com

Abbreviations: QC, Qianliening capsule; $\mathrm{BPH}$, benign prostatic hyperplasia; STAT3, signal transducer and activator of transcription 3; EGF, epidermal growth factor

Key words: Qianliening capsule, signal transducer and activator of transcription 3 pathway, cell proliferation and apoptosis, WPMY-1 cells, benign prostatic hyperplasia and western blot analysis, respectively. In the present study, QC was found to significantly and dose-dependently inhibit the EGF-stimulated growth of WPMY-1 cells, as evidenced by $\mathrm{QC}$-induced cell morphological changes and a reduction in cell viability. In addition, QC treatment markedly induced the activation of caspase- 9 and -3 . QC treatment also inhibited the EGF-mediated increase of STAT3 phosphorylation levels and transcriptional activity in WPMY-19 cells, accompanied by downregulation of the expression of Bcl-2, cyclin D1 and CDK4 and upregulation of the expression of Bax and p21. These results suggested that QC effectively inhibited the proliferation and promoted the apoptosis of human prostate cells via modulation of the STAT3 signaling pathway and its target genes, which is likely to be one of the mechanisms underlying its activity in BPH treatment.

\section{Introduction}

It has been demonstrated that the increase in the total number of stromal and epithelial prostatic cells due to the reduction of cell apoptosis and/or excessive cell proliferation, is associated with the development of benign prostatic hyperplasia (BPH) (1-3). BPH, a urinary system disease, is a common prostate disorder in older males with increasing incidence as average life span is prolonged in an ageing population $(4,5)$. $\mathrm{BPH}$ has become a major disease worldwide. The overgrown prostate gland causes increased resistance to urine flow, resulting in lower urinary tract symptoms (LUTS), including urinary hesitancy, frequent urination, urgency, thin urine flow and urinary retention (6). These symptoms have a marked effect on the physical and mental health of patients and affect their quality of life.

The pathogenesis of $\mathrm{BPH}$ is complex and remains to be elucidated. It has been widely accepted that the incidence and development of BPH is closely associated with disordered cell proliferation, the apoptosis of prostatic cells and dysregulation of several growth factors (7-12). Growth factors function via binding to their specific receptors, which activates the intracellular signal transduction system involved in the regulation of physiological function $(8,9)$. The signal transducer and activator of transcription 3 (STAT3) pathway is one of the main growth factor-mediated signal transduction pathways 
and is closely associated with the occurrence of BPH (13-15). Abnormal activation of the pathway can lead to a significant increase in the expression levels of the anti-apoptotic protein B-cell lymphoma 2 (Bcl-2) and the pro-proliferative protein cyclin D1, which in turn promote cell growth and the inhibition of apoptosis, which leads to the abnormal proliferation and malignant transformation of cells (16).

Epidermal growth factor (EGF) is an important factor in the promotion of mitosis and proliferation. Studies have demonstrated that EGF has an important effect on prostate growth and its abnormal expression is a key factor in BPH (16-18). EGF elicits its biological effects through binding to its receptor (EGFR). Upon interaction with EGF, the EGFR induces the phosphorylation/activation of STAT3, a transcription factor essential for cell survival and proliferation $(16,19,20)$. The phosphorylation of STAT3 in the cytoplasm induces its homodimerization, nuclear translocation and DNA binding, resulting in the expression of various essential genes involved in cell proliferation and survival (21-24). Therefore, the suppression of STAT3 activation has been a major focus in the development of novel treatments for BPH.

Natural products have been considered as alternative medicines for a number of years. Numerous plants and their constituents have been observed to possess beneficial therapeutic effects for various diseases, including BPH (25-28). Qianliening capsules (QC) are a Traditional Chinese Medicine and consist of a combination of rhubarb (Radix et Rhizoma Rhei), leech (Hirudo), Astragalus (Radix Astragali), Achyranthes (Radix Achyranthis bidentatae) and Dodder (Semen Cuscutae). These products together confer the QC properties of heat-clearance, detoxification, promotion of blood circulation, removal of blood stasis and tonfication of the kidney, the latter being considered to nourish vitality and referred to as replenishing the kidney qi in Chinese Medicine (29,30). It has been reported that QCs have significant therapeutic effects on BPH by improving a series of LUTS and the dynamic index of urine flow in patients with BPH $(29,31)$. In addition, studies involving animal experiments have demonstrated that QC significantly decreases the prostatic volume and weight and inhibits prostatic hyperplasia. Previous studies by our group have shown that this occurs by improving the abnormal ratio of estrogen to androgen in the serum via regulating the expression of estrogen receptor (ER) and androgen receptor (AR) (30), inhibiting the expression levels of pro-proliferative cyclin D1, proliferating cell nuclear antigen and cyclin-dependent kinase 4 (CDK4) via suppression of the EGF/STAT3 signaling pathway in vivo (16), and inducing prostatic cell apoptosis through the mitochondrion-dependent apoptotic pathway in vivo and in vitro $(32,33)$. However, the precise mechanism of its anti-BPH activity remains to be fully elucidated. To further investigate the mechanism underlying the activity of QC in the treatment of BPH, the present study investigated its effects on the EGF-mediated activities in human prostatic WPMY-1 cells, including cell proliferation and apoptosis, levels of phosphorylation, the transcriptional activity of STAT3 and the expression levels of several STAT3 signaling target genes. The present study investigated the effect of QC on the proliferation and apoptotic rate of WPMY-1 cells, phosphorylation and transcription of STAT3, as well as expression of the apoptosis-regulating proteins Bcl-2, cyclin D1, CDK4,
B-cell-associated X protein (Bax) and p21. Western blot and polymerase chain reaction (PCR) analyses, MTT assay, cell cycle analysis and a luciferase reporter assay were employed to elucidate the underlying mechanism of the activity of QC. To the best of our knowledge, the present study was the first to report that the effect of QC on the proliferation and apoptosis of WPMY-1 cells proceeds via interference with the STAT3 pathway, which is likely to be one of the mechanisms underlying its activity in the treatment of BPH.

\section{Materials and methods}

Materials and reagents. QC (Chinese Food and Drug Administration, approval no. Z09104065) was provided by the Academy of Pharmacology of Fujian University of Traditional Chinese Medicine (Fuzhou, China). QC were dissolved in phosphate-buffered saline (PBS) to a concentration of $0.5 \mathrm{~g} / \mathrm{ml}$ and stored at $4^{\circ} \mathrm{C}$. Dulbecco's modified Eagle's medium (DMEM), fetal bovine serum (FBS), penicillin-streptomycin, trypsin-EDTA and TRIzol reagent were purchased from Invitrogen Life Technologies (Carlsbad, CA, USA). SuperScript II reverse transcriptase was obtained from Promega Corporation (Madison, WI, USA). All antibodies were purchased from Cell Signaling Technologies, Inc, (Danvers, MA, USA). The EGF and all other chemicals used, unless otherwise stated, were obtained from Sigma-Aldrich (St. Louis, MO, USA).

Cell culture. Human prostate stromal WPMY-1 cells were obtained from the Cell Bank of the Chinese Academy of Science (Shanghai, China). The cells were grown in DMEM containing $10 \%$ (v/v) FBS, 100 units $/ \mathrm{ml}$ penicillin and $100 \mu \mathrm{g} / \mathrm{ml}$ streptomycin in a $37^{\circ} \mathrm{C}$ humidified incubator with $5 \% \mathrm{CO}_{2}$.

Evaluation of cell viability by MTT assay. The WPMY-1 cells were seeded into 96-well plates at a density of $1.0 \times 10^{4}$ cells/well in $0.1 \mathrm{ml}$ medium. After $24 \mathrm{~h}$, with the exception of the control group, the cells were stimulated with $10 \mathrm{ng} / \mathrm{ml}$ EGF and treated with different concentrations of QC $(1,3$ and $5 \mathrm{mg} / \mathrm{ml})$ for $24 \mathrm{~h}$. Subsequently, $10 \mu \mathrm{l} \mathrm{MTT} \mathrm{(5} \mathrm{mg/ml} \mathrm{in} \mathrm{PBS)} \mathrm{was} \mathrm{added}$ to each well and the samples were incubated for an additional $4 \mathrm{~h}$ at $37^{\circ} \mathrm{C}$. The purple-blue MTT formazan precipitate was dissolved in $0.1 \mathrm{ml}$ dimethyl sulfoxide and the absorbance was measured at $570 \mathrm{~nm}$ using an ELISA reader (EXL800; BioTek Instruments, Inc., Winooski, VT, USA).

Observation of morphological changes. The WPMY-1 cells were seeded into 12 -well plates at a density of $1.0 \times 10^{5}$ cells $/ \mathrm{ml}$ in $1 \mathrm{ml}$ medium. After $24 \mathrm{~h}$, with the exception of the control group, the cells were stimulated with EGF $(10 \mathrm{ng} / \mathrm{ml})$ and treated with various concentrations of QC $(1,3$ and $5 \mathrm{mg} / \mathrm{ml})$ for $24 \mathrm{~h}$. The cell morphology was observed using a phase-contrast microscope (DM4000B; Leica Microsystems, Wetzlar, Germany) and images were captured at a magnification of $\mathrm{x} 200$.

Detection of apoptosis by Annexin V/propidium iodide (PI) staining. The WPMY-1 cells were seeded into six-well plates at a density of $1.0 \times 10^{5}$ cells $/ \mathrm{ml}$ in $2 \mathrm{ml}$ medium. After $24 \mathrm{~h}$, 
the cells were stimulated with EGF $(10 \mathrm{ng} / \mathrm{ml})$ and treated with various concentrations of QC for $24 \mathrm{~h}$. Following incubation with various concentrations of QC (1,3 and $5 \mathrm{mg}$ / $\mathrm{ml}$ ), the apoptotic rate of WPMY-1 cells was determined by flow cytometric analysis using FACSCalibur flow cytometer (Becton-Dickinson, San Jose, CA, USA) and an Annexin V-fluoresceinisothiocyanate(FITC)/PIkit(Becton-Dickinson). Staining was performed according to the manufacturer's instructions. The percentage of cells in early apoptosis was determined via quantification of Annexin V-positive and PI-negative cells, while Annexin V-positive and PI-positive cells were regarded to be in late apoptosis.

Detection of cell cycle distribution by PI staining. The WPMY-1 cells were seeded into a six-well plate at a density of $1.0 \times 10^{5}$ cells $/ \mathrm{ml}$ in $2 \mathrm{ml}$ medium. After $24 \mathrm{~h}$, with the exception of the control group, the cells were stimulated with EGF and treated with various concentrations of QC for $24 \mathrm{~h}$. After $24 \mathrm{~h}$, the cells were harvested, adjusted to a concentration of $1 \times 10^{6}$ cells $/ \mathrm{ml}$ and fixed in $70 \%$ ethanol at $4^{\circ} \mathrm{C}$ overnight. The fixed cells were washed twice with cold PBS and incubated with RNase $(8 \mu \mathrm{g} / \mathrm{ml})$ and PI $(10 \mu \mathrm{g} / \mathrm{ml})$ for $30 \mathrm{~min}$ in the dark. The cell cycle distribution was detected by flow cytometric analysis and the proportion of DNA in different phases was analyzed using Modfit LT 3.0 software (Verity Software House, Topsham, ME, USA).

Analysis of caspase-9 and caspase-3 activation. The activation of caspase-3 and -9 was determined using a colorimetric assay with caspase- 9 and -3 activation kits (Invitrogen Life Technologies) according to the manufacturer's instructions. Briefly, following treatment with various concentrations of QC for $24 \mathrm{~h}$, the EGF-stimulated WPMY-1 cells were lysed with mammalian cell lysis buffer, containing 20 mM Tris- $\mathrm{HCl}$ (pH 7.4), $150 \mathrm{mM} \mathrm{NaCl}, 2 \mathrm{mM}$ ethylenediaminetetraacetic acid, 1\% Nonidet P-40, $50 \mathrm{mM} \mathrm{NaF}$ and $1 \mathrm{X}$ protease inhibitor, for $30 \mathrm{~min}$ on ice. The lysed cells were centrifuged at $16,000 \mathrm{x} \mathrm{g}$ for $10 \mathrm{~min}$ and $100 \mu \mathrm{g}$ protein was incubated with $50 \mu 1$ of the colorimetric tetrapeptides, Asp-Glu-Val-Asp (DEVD)-p-nitroaniline (pNA), a specific substrate of caspase-3 or Leu-Glu-His-Asp (LEHD)-pNA, a specific substrate of caspase- 9 , at $37^{\circ} \mathrm{C}$ in the dark for $2 \mathrm{~h}$. The samples were read at $405 \mathrm{~nm}$ using an ELISA reader (EXL800; BioTek Instruments, Inc.). The data were normalized to the activity of the caspases in the control cells, which were treated with the PBS vehicle, and expressed as the fold-change compared with the control.

Luciferase genereporter assay. The WPMY-1 cells were seeded into 96-well plates at a density of $1 \times 10^{4}$ cells/well in $0.1 \mathrm{ml}$ complete DMEM until they reached $\sim 60 \%$ confluency and then continuously cultured in FBS- and antibiotic-free medium overnight. The cells were transfected with a mixture of inducible STAT3-responsive firefly luciferase and constitutively expressing Renilla luciferase using Lipofectamine ${ }^{\mathrm{TM}}$ LTX with PLUS ${ }^{\text {тм }}$ Reagent. Subsequently, $6 \mathrm{~h}$ after transfection, the medium was changed back to complete DMEM with FBS, penicillin and streptomycin. After $24 \mathrm{~h}$ of transfection, the cells were treated with various contractions of QC $(1,3$ and $5 \mathrm{mg} / \mathrm{ml}$ ) for $1 \mathrm{~h}$ followed by EGF for another $24 \mathrm{~h}$. The cell

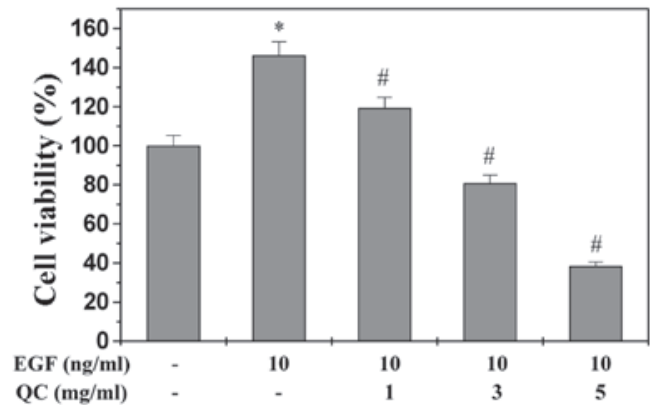

Figure 1. Effect of QC on the viability of WPMY-1 cells stimulated with EGF. WPMY-1 cells stimulated with EGF were treated with indicated concentrations of QC $(1,3$ or $5 \mathrm{ml} / \mathrm{ml})$ for $24 \mathrm{~h}$. The cell viability was determined using an MTT assay. The data were normalized to the viability of the control cells. Data are expressed as the mean \pm standard deviation (error bars) from at least three independent experiments. ${ }^{*} \mathrm{P}<0.05$, vs. control cells; ${ }^{\sharp} \mathrm{P}<0.05$, vs. cells treated with EGF but without QC. QC, Qianliening capsules; EGF, epidermal growth factor.

extracts were prepared and analyzed using the Promega Dural Luciferase Reporter Assay system according to the manufacturer's instructions. The firefly luciferase activity measured was normalized to that of Renilla luciferase in the same well.

$R N A$ extraction and $R T-q P C R$ analysis. A total of $1 \times 10^{5}$ WPMY-1 cells were seeded into 12-well plates. After $24 \mathrm{~h}$, the cells were stimulated with EGF and treated with various concentrations of QC $(1,3$ and $5 \mathrm{mg} / \mathrm{ml})$ for $24 \mathrm{~h}$. The total RNA from the WPMY-1 cells was isolated using TRIzol reagent (Invitrogen Life Technologies). Oligo(dT)-primed RNA $(1 \mu \mathrm{g})$ was reverse-transcribed with SuperScript II reverse transcriptase (Promega Corporation) according to the manufacturer's instructions. The cDNA obtained was used to determine the mRNA expression levels of Bcl-2, Bax, cyclin D1, CDK4 and p21 by PCR with Taq DNA polymerase (Fermentas, Pittsburgh, PA, USA). GAPDH was used as an internal control. The primers used for amplification of Bcl-2, Bax, Cyclin D1, CDK4, p21 and GAPDH transcripts are as described previously $(33,34)$. The samples were analyzed by gel electrophoresis (1.5\% agarose) and the DNA bands were examined using a gel documentation system (Gel Doc XR+; Bio-Rad, Hercules, CA, USA).

Western blot analysis. The WPMY-1 cells were seeded into a $25 \mathrm{~cm}^{2}$-culture bottle at a density of $1.0 \times 10^{5}$ cells $/ \mathrm{ml}$ in $5 \mathrm{ml}$ medium. After $24 \mathrm{~h}$, the cells were stimulated with EGF and treated with various concentrations of QC for $24 \mathrm{~h}$. The treated cells were lysed in mammalian cell lysis buffer (M-PER; Thermo Fisher Scientific, Rockford, IL, USA) containing protease (EMD Biosciences, La Jolla, CA, USA) and phosphatase inhibitor (Sigma-Aldrich) cocktails and centrifuged at $14,000 \mathrm{xg}$ for $15 \mathrm{~min}$. The protein concentrations in the cell lysate supernatants were determined using a Bicinchoninic Acid Protein Assay kit (Tiangen Biotech Co., Ltd, Beijing, China). Equal quantities of protein $(20 \mu \mathrm{g})$ from each tumor or cell lysate were resolved on $12 \%$ Tris-glycine gels and transferred onto polyvinylidene difluoride membranes. The membranes were inhibited for $2 \mathrm{~h}$ with $5 \%$ non-fat dry milk and incubated with the desired primary monoclonal antibodies directed against STAT3, phosphorylated (p)-STAT3, Bcl-2, 


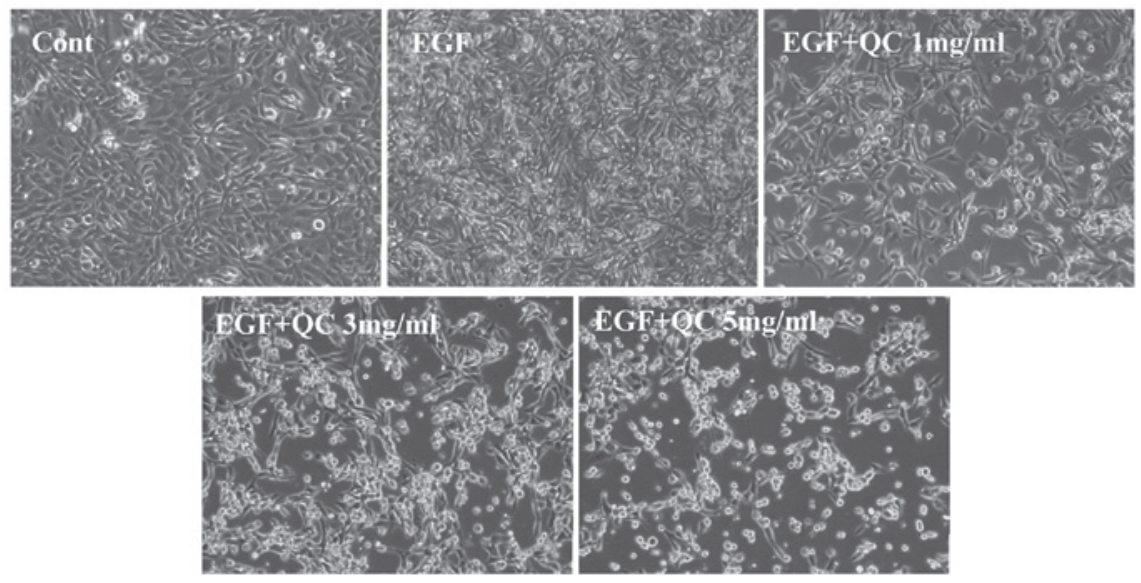

Figure 2. Effect of QC on the cell density of WPMY-1 cells stimulated with EGF. Phase-contrast microscopy was used to observed the density of the WPMY-1 cells stimulated with EGF following treatment with different concentrations of QC (1,3 or $5 \mathrm{ml} / \mathrm{ml}$ ) for $24 \mathrm{~h}$ (magnification, x200). Images are representative of three independent experiments. QC, Qianliening capsules; EGF, epidermal growth factor; Cont, control.
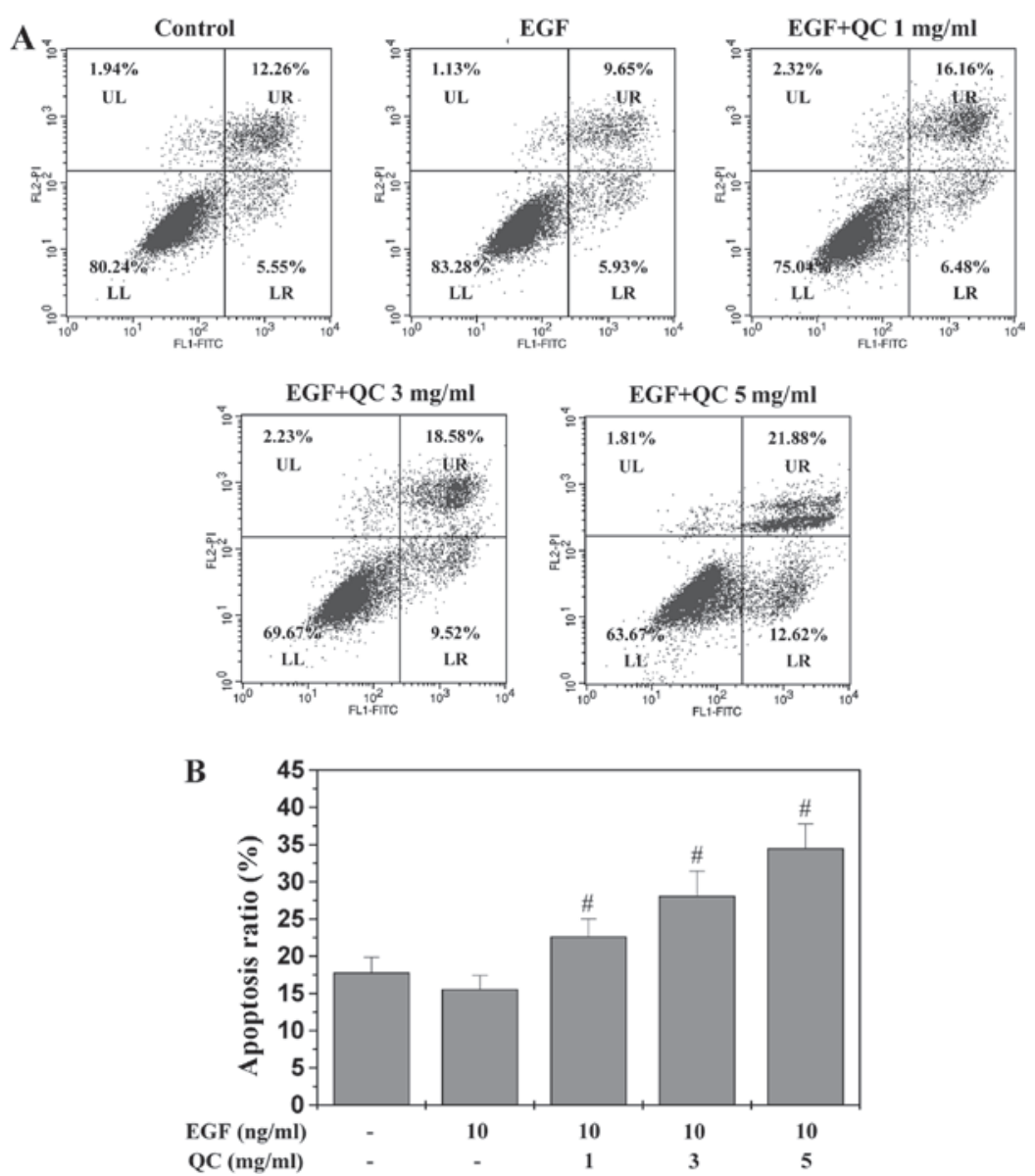

Figure 3. Effect of QC on the apoptosis of WPMY-1 cells stimulated with EGF. (A) WPMY-1 cells stimulated with EGF were treated with the indicated concentrations of QC (1,3 or $5 \mathrm{ml} / \mathrm{ml})$ for $24 \mathrm{~h}$, collected and stained with Annexin V/PI followed by FACS analysis. Representative FACS analysis scatter-grams of Annexin V/PI staining reveals four cell populations: Double-negative stained cells (LL) indicating the live cell population; Annexin V-positive/PI-negative stained cells (LR); Annexin V/PI double-positive stained cells (UR) representing early and late apoptosis, respectively, and Annexin V-negative and PI-positive stained cells (UL) indicating dead cells. Dot plots are representative of three independent experiments. (B) Quantification of FACS analysis. Data are expressed as the mean \pm standard deviation (error bars) from three independent experiments. ${ }^{~} \mathrm{P}<0.05$, vs. cells treated with EGF but without QC. QC, Qianliening capsules; EGF, epidermal growth factor; FACS, fluorescence-activated cell sorting; LL, lower left; LR, lower right; UR, upper right; UL, upper left; FITC, fluorescein isothiocyanate; PI, propidium iodide.

Bax, cyclin D1, CDK4, p21 and $\beta$-actin (all 1:1,000) overnight at $4^{\circ} \mathrm{C}$. Appropriate horseradish peroxidase-conjugated secondary antibodies with chemiluminescence detection were used to image the antibody-detected proteins. The membranes were analyzed using Enhanced eyeECL Plus reagents and scanned using a Storm PhosphorImager (Chemi Doc XRS+; Bio-Rad).

Statistical analysis. Data are expressed as the mean \pm standard deviation for the indicated number of independently performed 

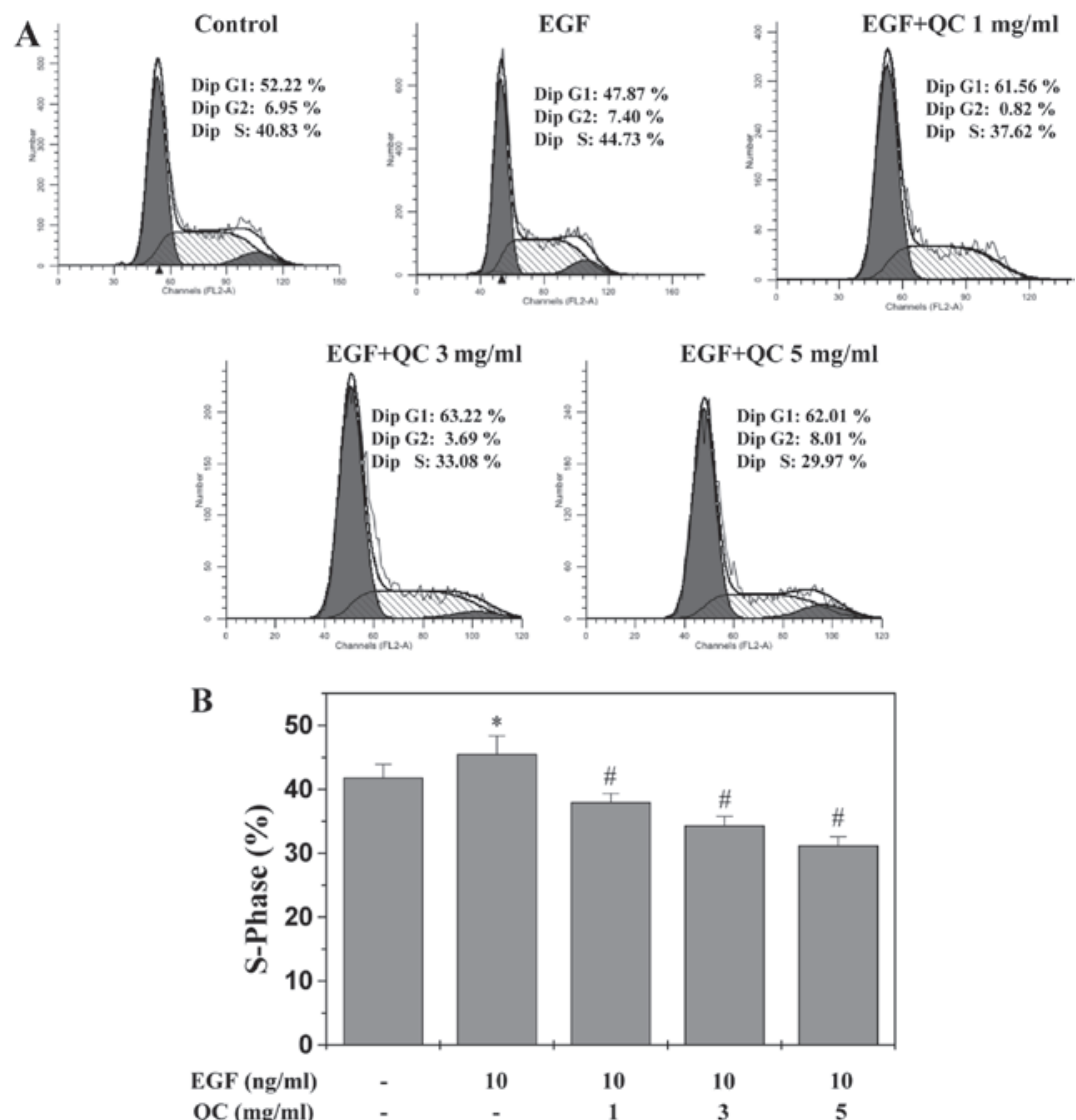

Figure 4. Effect of QC on the cell cycle progression of WPMY-1 cells stimulated with EGF. (A) WPMY-1 cells stimulated with EGF were treated with the indicated concentrations of QC $(1,3$ or $5 \mathrm{ml} / \mathrm{ml})$ for $24 \mathrm{~h}$, stained with propidium iodide and analyzed by fluorescence-activated cell sorting. Images are representative of three independent experiments. (B) Proportion of DNA in S-phase, calculated using ModfitLT Version 3.0 Software. Data are expressed as the mean \pm standard deviation (error bars) from three independent experiments. ${ }^{*} \mathrm{P}<0.05$, vs. control cells; ${ }^{*} \mathrm{P}<0.05$, vs. cells treated with EGF but without $\mathrm{QC}$. QC, Qianliening capsules; EGF, epidermal growth factor; Dip, diploid.

experiments. The data were analyzed using SPSS 17.0 software for Windows (SPSS, Inc., Chicago, IL, USA). Statistical analyses were performed using Student's t-test and analysis of variance. $\mathrm{P}<0.05$ was considered to indicate a statistically significant difference.

\section{Results}

QC inhibits the growth of WPMY-1 cells. Since the development of BPH is associated with a reduction in prostatic cell apoptosis and/or excessive cell proliferation and EGF is one of the essential growth factors in promoting the proliferation and inhibiting the apoptosis of prostatic cells, the present study used EGF to stimulate the growth of the WPMY-1 human prostate stromal cell line. As expected, upon stimulation with $10 \mathrm{ng} / \mathrm{ml}$ EGF, the viability of the WPMY-1 cells increased to $145 \%$ of that of the control cells $(\mathrm{P}<0.01$; Fig. 1). However, treatment with $1-5 \mathrm{mg} / \mathrm{ml} \mathrm{QC}$ for $24 \mathrm{~h}$ led to a dose-dependent reduction in the viability of EGF-stimulated cells $(\mathrm{P}<0.01)$. To further confirm these results, the effect of QC on WPMY-1 cell morphology was assessed via phase-contrast microscopy, since the morphology of cells in culture is indicative of the health status of the cells. As shown in Fig. 2, QC treatment led to a dose-dependent reduction in WPMY-1 cell density. These data demonstrated that QC inhibited the growth of EGF-stimulated WPMY-1 cells.
QC induces apoptosis of WPMY-1 cells. The QC-induced apoptosis of the WPMY-1 cells was examined in vitro using Annexin-V/PI staining followed by flow cytometric analysis. As shown in Fig. 3A and B, no significant decrease was observed in the apoptotic rate of WPMY-1 cells stimulated with $10 \mathrm{ng} / \mathrm{ml}$ EGF compared with that of the control cells ( $\mathrm{P}>0.05)$. However, QC treatment dose-dependently increased the percentage of cells undergoing apoptosis, demonstrated as early apoptosis in the lower right and late apoptosis in the upper right quadrants in the dot plots $(\mathrm{P}<0.05$, vs. EGF-stimulated cells without QC treatment) (Fig. 3A).

QC inhibits G1/S phase transition of WPMY-1 cells. The $\mathrm{G} 1 / \mathrm{S}$ transition is one of the two main checkpoints used by cells to regulate the cell cycle progression and, thus, cell proliferation (35). The present study investigated the effect of QC on the G1- to S-phase transition in the WPMY-1 cells via PI staining followed by flow cytometric analysis. As shown in Fig. 4, the proportion of WPMY-1 cells in S-phase following stimulation with EGF (45.52 $\pm 2.83 \%)$ was markedly increased compared with that of the control cells $(41.83 \pm 2.07 \% ; \mathrm{P}<0.05$; Fig. 4). However, treatment with 1,3 and $5 \mathrm{mg} / \mathrm{ml}$ QC for $24 \mathrm{~h}$ led to a dose-dependent reduction in the proportion of the EGF-stimulated cells in S-phase $(37.98 \pm 1.38,34.34 \pm 1.44$ and $31.22 \pm 1.34 \%$, respectively), compared with that of the EGF-stimulated cells without QC treatment (45.52 \pm 2.83 ; 

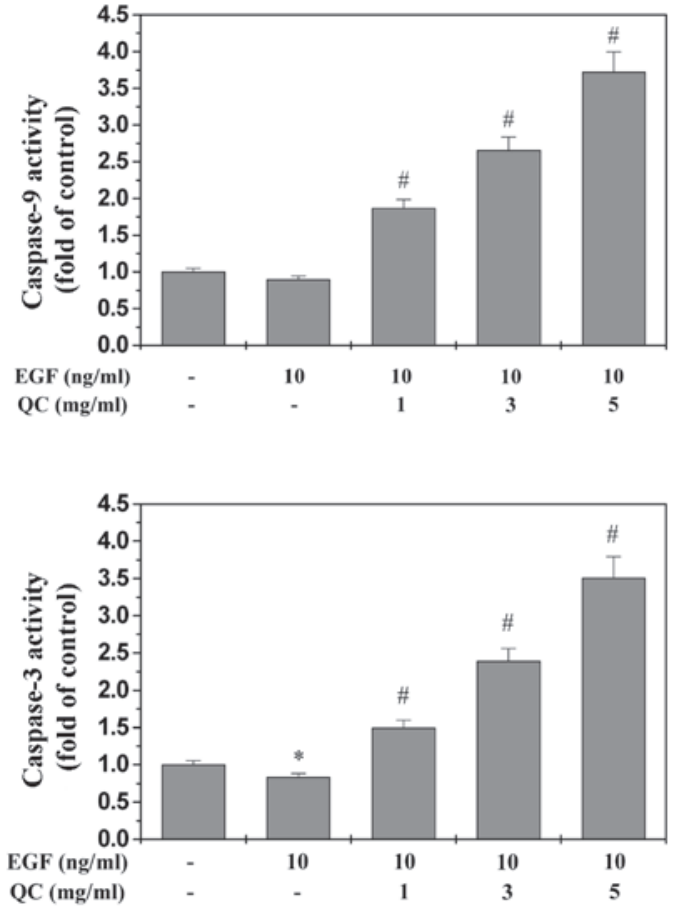

Figure 5. Effect of QC on the activity of caspases in WPMY-1 cells stimulated with EGF. The cells stimulated with EGF were treated with the indicated concentrations of QC $(1,3$ or $5 \mathrm{ml} / \mathrm{ml})$ for $24 \mathrm{~h}$. The activities of caspase- 9 and -3 were determined using a colorimetric assay. The data were normalized to the caspase activities within the control cells and expressed as the 'fold of control'. Data are expressed as the mean \pm standard deviation (error bars) from at least three independent experiments. ${ }^{*} \mathrm{P}<0.05$, vs. control cells; ${ }^{~} \mathrm{P}<0.05$, vs. cells treated with EGF but without QC. QC, Qianliening capsules; EGF, epidermal growth factor.

$\mathrm{P}<0.01)$. These results indicated that $\mathrm{QC}$ inhibited the WPMY-1 cell proliferation by inhibiting cell cycle progression by blocking the G1- to S-phase transition.

QC induces the activation of caspase-9 and - 3 in WPMY- 1 cells. The activation of caspase- 9 and -3 was examined using a colorimetric assay with the chromophores LEHD-pNA, a specific substrate of caspase-9 and DEVD-pNA, a specific substrate of caspase-3. Caspases, cytoplasmic aspartate-specific cysteine proteases, are key proteins in the apoptotic response. Caspase- 9 can activate caspase-3, which triggers targeting and degradation of specific and vital cellular proteins. Subsequently, the degradation of nuclear DNA and apoptotic cell death occurs. Therefore, the activation of caspases is important in the process of apoptosis. As shown in Fig. 5A and B, QC treatment significantly and dose-dependently induced activation of caspase-9 and -3 in WPMY- 1 cells $(\mathrm{P}<0.01$, vs EGF-stimulated cells without $\mathrm{QC}$ treatment). In addition, EGF significantly inhibited the activation of caspase-3 (Fig. 5B).

QC inhibits the activation of the STAT3 signaling pathway in WPMY-1 cells. Previous studies have demonstrated that EGF stimulates STAT3 activation, which upregulates the levels of phosphorylated STAT3 in BPH prostatic cells (16-20). Therefore, in the present study, STAT3 activation in WPMY-1 cells was stimulated with EGF. The activation of STAT3 was determined by western blot analysis using an antibody which recognizes STAT3 phosphorylated at Tyr705 (pSTAT3). As
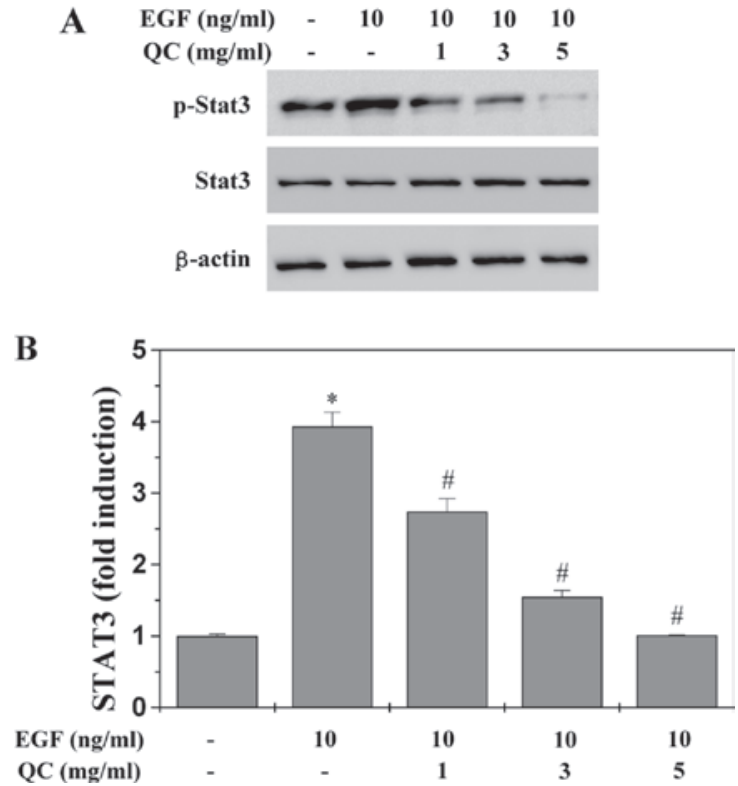

Figure 6. Effect of QC on STAT3 phosphorylation and transcriptional activity in WPMY-1 cells. (A) Cells stimulated with EGF were treated with the indicated concentrations of QC $(1,3$ or $5 \mathrm{ml} / \mathrm{ml})$ for $24 \mathrm{~h}$. STAT3 phosphorylation was determined by western blot analysis using an antibody that recognizes phosphorylated STAT3 at Tyr705. $\beta$-actin was used as the internal control. Data are representative of three independent experiments. (B) Cells were transfected with a mixture of inducible STAT3-responsive firefly luciferase construct and constitutively expressing Renilla luciferase construct (40:1). After $24 \mathrm{~h}$ of transfection, the cells were treated with various concentrations of QC $(1,3$ or $5 \mathrm{ml} / \mathrm{ml})$ for $1 \mathrm{~h}$ followed by EGF for another $24 \mathrm{~h}$. The transcriptional activity of STAT3 was measured using a dual luciferase reporter assay. Data are expressed as the mean \pm standard deviation (error bars) from at least three independent experiments. ${ }^{*} \mathrm{P}<0.05$, vs. control cells; ${ }^{\prime} \mathrm{P}<0.05$, vs. cells treated with EGF but without QC. QC, Qianliening capsules; EGF, epidermal growth factor; STAT3, signal transducer and activator of transcription 3.
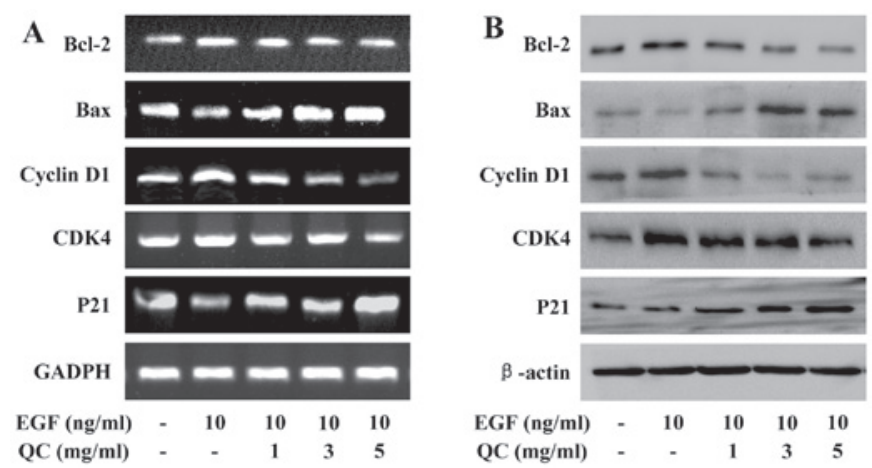

Figure 7. Effect of QC on the expression of Bcl-2, Bax, Cyclin D1, CDK4 and p21 in WPMY-1 cells stimulated with EGF. The WPMY-1 cells stimulated with EGF were treated with indicated concentrations of QC $(1,3$ or $5 \mathrm{ml} / \mathrm{ml})$ for $24 \mathrm{~h}$. (A) mRNA levels of Bcl-2, Bax, Cyclin D1, CDK4 and p21 were determined by RT-qPCR. (B) Protein expression levels of Bcl-2, Bax, cyclin D1, CDK4 and p21 were analyzed by western blot analysis. GAPDH and $\beta$-actin were used as the internal controls for the RT-qPCR and western blot assays, respectively. Data are representative of three independent experiments. QC, Qianliening capsules; EGF, epidermal growth factor; Bcl-2, B-cell lymphoma 2; Bax, Bcl-2-associated X protein; CDK4, cyclin-dependent kinase 4; RT-qPCR, reverse transcription quantitative polymerase chain reaction.

shown in Fig. 6A, stimulation with $10 \mathrm{ng} / \mathrm{ml}$ EGF significantly increased the levels of pSTAT3 in the WPMY-1 cells, which, however, was profoundly inhibited by QC in a dose-dependent manner. The levels of non-phosphorylated STAT3 remained 
unchanged following treatment with EGF and/or QC. To further confirm the inhibitory effect of QC on the activation of STAT3, a dual luciferase reporter assay was used to examine the transcriptional activity of STAT3. As shown in Fig. 6B, QC significantly and dose-dependently inhibited the EGF-stimulated increase in STAT3 transcriptional activity. These data suggested that QC was potent in inhibiting EGF-mediated STAT3 activation in human prostatic cells.

$Q C$ regulates the expression of $B c l-2$, Bax, cyclin D1, CDK4 and p21 in WPMY-1 cells. To further investigate the mechanisms underlying the activities of QC, RT-qPCR and western blot analyses were performed to examine the effect of QC on the expression of anti-apoptotic Bcl-2, pro-apoptotic Bax, pro-proliferative cyclin D1 and CDK4, as well as anti-proliferative p21, which are important target genes of the STAT3 signaling pathway. As Fig. 7 shows, the mRNA and protein expression levels of Bcl-2, cyclin D1 and CDK4 were markedly increased by EGF stimulation and the expression levels of Bax and p21 were markedly reduced by EGF stimulation. However, QC treatment profoundly inhibited the EGF-induced upregulation of Bcl-2, cyclin D1 and CDK4 and increased the EGF-induced downregulation of Bax and p21 at the transcriptional and translational levels.

\section{Discussion}

$\mathrm{BPH}$ is a non-cancerous enlargement of the prostate and is characterized by excessive and uncontrolled growth of the epithelial and stromal cells of the prostate gland. It is an age-associated disease and is present in $50 \%$ of men by the age of 50 and $80 \%$ by the age of 70 (4). To date, BPH treatment includes surgery and medication, although there is no completely effective treatment for BPH. Surgical therapy may have improved efficacy, but pharmacotherapy remains the most common option for BPH treatment. Pharmacotherapies consist of $\alpha$-blockers, including Terazosin, Doxazosin and Tamsulosin, which inhibit $\alpha$-adrenergic receptors and $5 \alpha$-reductase inhibitors, including Finasteride and Dutasteride, which inhibit the production of dihydrotestosterone by suppressing $5 \alpha$-reductase $(36,37)$. Although all may reduce the tissue enlargement and decrease the blockage of urine flow, they also have their own side effects, including orthostatic hypotension, reduced libido and ejaculation or erectile dysfunction $(38,39)$. Therefore, there is an urgent requirement for the development of novel agents without or with fewer side effects and toxicity for BPH treatment. Natural products, including Traditional Chinese Medicines, usually generate fewer adverse effects and exhibit therapeutic efficacy $(25-28,40)$.

QC are a Traditional Chinese Medicinal formulation, which has been used clinically in China for numerous years, exhibiting significant efficacy in BPH treatment (16,30-33). However, the mechanism underlying its anti-BPH activity remains to be fully elucidated. In the present study, the WPMY-1 cell line, derived from stromal cells of the normal adult prostate, was treated with different concentrations of QC following stimulation with EGF in order to clarify the potential molecular mechanisms of the activity of QC in BPH treatment. The present study, for the first time, to the best of our knowledge, demonstrated that QC reduced cell viability, arrested cell cycle through inhibition of G1-phase progression, induced the activation of caspase- 9 and -3 , inhibited the proliferation and induced the apoptosis of the EGF-stimulated WPMY-1 cells in a dose-dependent manner. Furthermore, the mechanism underlying the effects of QC on the WPMY-1 cells proceeded via the STAT3 pathway.

$\mathrm{BPH}$ is the pathological, upregulated proliferation of prostatic cells and a variety of growth factors, including EGF, are inculpated in its pathogenesis. EGF stimulates the activation of STAT3 via binding to the EGF receptor $(16,19)$. STAT3 is one of the main cellular signaling transduction pathways known to be closely associated with the development of BPH (13-15). The activation of STAT3 is mediated by phosphorylation at Tyr 705, leading to its homodimerization, nuclear translocation and DNA binding, which in turn regulates the expression of various genes involved in cell proliferation and survival, including up-regulation of the expression of pro-proliferative cyclin D1, CDK4 and anti-apoptotic Bcl-2 or down-regulation of the expression of anti-proliferative $\mathrm{p} 21$ and pro-apoptotic Bax (19-24). The aberrant activation of STAT3 leads to increased cell proliferation and reduced cell apoptosis, resulting in BPH development. Therefore, modulation of STAT3 signaling has been a promising target for the development of anti-BPH therapies $(16,41)$.

In the present study, human prostatic WPMY-1 cells were stimulated with EGF and the results revealed that the activation of STAT3 was clearly increased upon EGF stimulation, leading to a significant increase in its phosphorylation levels and transcriptional activity. However, the EGF-mediated STAT3 activation was profoundly inhibited by QC treatment in a dose-dependent manner. Consequently, QC treatment significantly inhibited the EGF-induced up-regulation of cyclin D1, CDK4 and Bcl-2, and increased the EGF-induced downregulation of p21 and Bax, which are key target genes of the STAT3 pathway.

In conclusion, the present study reported for the first time, to the best of our knowledge, that QC inhibited the growth of WPMY-1 cells and induced their apoptosis via inhibition of the STAT3 pathway in vitro, which may be one of the mechanisms underlying the activity of QC in the treatment of BPH.

\section{Acknowledgements}

This study was supported by the Nature Science Foundation of China (nos. 81173433, 81273928 and 81373817).

\section{References}

1. Sirab N, Robert G, Fasolo V, et al: Lipidosterolic extract of Serenoa repens modulates the expression of inflammation related-genes inbenign prostatic hyperplasia epithelial and stromal cells. Int J Mol Sci 14: 14301-14320, 2013.

2. Atawia RT, Tadros MG, Khalifa AE, Mosli HA and Abdel-Naim AB: Role of the phytoestrogenic, pro-apoptotic and anti-oxidative properties of silymarin in inhibiting experimental benign prostatic hyperplasia in rats. Toxicol Lett 219: 160-169, 2013.

3. Pollan MC, Benghuzzi HA and Tucci M: Growth factor expression in early stages of benign prostatic hyperplasia upon exposure to sustained delivery of androgens. Biomed Sci Instrum 39: 329-334, 2003

4. Paolone DR: Benign prostatic hyperplasia. Clin Geriatr Med 26: 223-239, 2010. 
5. Roehrborn CG: Male lower urinary tract symptoms (LUTS) and benign prostatic hyperplasia (BPH). Med Clin North Am 95: 87-100, 2011

6. Gat Y, Gornish M, Heiblum M and Joshua S: Reversal of benign prostate hyperplasia by selective occlusion of impaired venous drainage in the male reproductive system: novel mechanism, new treatment. Andrologia 40: 273-281, 2008.

7. Steiner MS: Review of peptide growth factors in benign prostatic hyperplasia and urological malignancy. J Urol 153: 1085-1096, 1995.

8. Wang Z and Olumi AF: Diabetes, growth hormone-insulin-like growth factor pathways and association to benign prostatic hyperplasia. Differentiation 82: 261-271, 2011.

9. Descazeaud A, Weinbreck N, Robert G, et al: Transforming growth factor $\beta$-receptor II protein expression in benign prostatic hyperplasia is associated with prostate volume and inflammation. BJU Int 108: E23-E28, 2011.

10. Voss M, Trojan L, Steidler A, et al: Serum vascular endothelial growth factor $\mathrm{C}$ level in patients with prostate cancer and benign prostatic hyperplasia. Anal Quant Cytol Histol 30: 199-202, 2008.

11. Ma Z, Tsuchiya N, Yuasa T, et al: Polymorphisms of fibroblast growth factor receptor 4 have association with the development of prostate cancer and benign prostatic hyperplasia and the progression of prostate cancer in a Japanese population. Int J Cancer 123: 2574-2579, 2008.

12. Wang W,Zhang X, Mize GJ and Takayama TK: Protease-activated receptor-1 upregulates fibroblast growth factor 7 in stroma of benign prostatic hyperplasia. Prostate 68: 1064-1075, 2008

13. Haura EB, Turkson J and Jove R: Mechanisms of disease: Insights into the emerging role of signal transducers and activators of transcription in cancer. Nat Clin Pract Oncol 2: 315-324, 2005.

14. Siejka A, Schally AV, Block NL and Barabutis N: Antagonists of growth hormone-releasing hormone inhibit the proliferation of human benign prostatic hyperplasia cells. Prostate 70: 1087-1093, 2010.

15. Siejka A, Schally AV, Block NL and Barabutis N: Mechanisms of inhibition of human benign prostatic hyperplasia in vitro by the luteinizing hormone-releasing hormone antagonist cetrorelix. BJU Int 106: 1382-1388, 2010.

16. Lin JM, Zhou JH, Xu W, et al: Qianliening capsule treats benign prostatic hyperplasia via suppression of the EGF/STAT3 signaling pathway. Exp Ther Med 5: 1293-1300, 2013.

17. Lin J, Hong Z, Zhou H, et al: Expression of the growth factor related to angiogenesis on the prostatic hyperplasia in rats J Fujian Univ Tradit Chin Med 18: 63-65, 2008 (In Chinese).

18. Jia bin, Tang Hong, Li Weimin and Cai Wenqing: The effects of epidermal growth factor on the expression of Bcl-2, Bax and c-myc in mice prostate cells. Chin J Gerontol 27: 251-252, 2007 (In Chinese).

19. Park OK, Schaefer TS and Nathans D: In vitro activation of STAT3 by epidermal growth factor receptor kinase. Proc Natl Acad Sci USA 93: 13704-13708, 1996.

20. Zhong Z, Wen Z and Darnell JE Jr: Stat3: a STAT family member activated by tyrosine phosphorylation in response to epidermal growth factor and interleukin-6. Science 264: 95-98, 1994.

21. Catlett-Falcone R, Landowski TH, Oshiro MM, et al: Constitutive activation of Stat 3 signaling confers resistance to apoptosis in human U266 myeloma cells. Immunity 10: 105-115, 1999.

22. Karni R, Jove R and Levitzki A: Inhibition of pp60c-Src reduces Bcl-XL expression and reverses the transformed phenotype of cells overexpressing EGF and HER-2 receptors. Oncogene 18: 4654-4662, 1999.

23. Coqueret $\mathrm{O}$ and Gascan H: Functional interaction of STAT3 transcription factor with the cell cycle inhibitor p21WAF1/CIP1/SDI1. J Biol Chem 275: 18794-18800, 2000.
24. Bienvenu F, Gascan H and Coqueret O: Cyclin D1 represses STAT3 activation through a Cdk4-independent mechanism. J Biol Chem 276: 16840-16847, 2001.

25. Huang YP, Du J, Hong ZF, et al: Effects of Kangquan recipe on sex steroids and cell proliferation in rats with benign prostatic hyperplasia. Chin J Integr Med 15: 289-292, 2009.

26. Boyle P, Robertson C, Lowe F and Roehrborn C: Meta-analysis of clinical trials of Permixon in the treatment of symptomatic benign prostatic hyperplasia. Urology 55: 533-539, 2000.

27. Vacherot F, Azzouz M, Gil-Diez-De-Medina S, et al: Induction of apoptosis and inhibition of cell proliferation by the lipido-sterolic extract of Serenoa repens (LSESr, Permixon) in benign prostatic hyperplasia. Prostate 45: 259-266, 2000.

28. Quiles MT, Arbós MA, Fraga A, et al: Antiproliferative and apoptotic effects of the herbal agent Pygeum africanum on cultured prostate stromal cells from patients with benign prostatic hyperplasia (BPH). Prostate 70: 1044-1053, 2010.

29. Lin JM, Huang YP, Zhou Jh and Hong ZF: Therapeutic efficacy of Qianliening capsules in the treatment of benign prostatic hyperplasia. Asia-Pacific Traditional Medicine 9: 140-143, 2013 (In Chinese)

30. Zhou J, Lin J, Xu W, et al: Qianliening capsule treats benign prostatic hyperplasia through regulating the expression of sex hormones, estrogen receptor and androgen receptor. Afr J Pharm and Pharmacol 6: 173-180, 2012

31. Zhong X, Lin J, Zhou J, et al: Qianliening capsule treats benign prostatic hyperplasia (BPH) by down-regulating the expression of PCNA, CyclinD1 and CDK4. Afr J Biotechnol 11: 7731-7737, 2012

32. Zheng HY, Xu W, Lin JM, Peng J and Hong ZF: Qianliening capsule treats benign prostatic hyperplasia via induction of prostatic cell apoptosis. Mol Med Rep 7: 848-854, 2013.

33. Hong ZF, Lin JM, Zhong XY, et al: Qianliening capsule inhibits human prostate cell growth via induction of the mitochondriondependent cell apoptosis. Chin J Integr Med 18: 824-830, 2012.

34. Lin JM, Chen YQ, Cai QY, et al: Scutellaria barbata D Don inhibits colorectal cancer growth via suppression of multiple signaling pathways. Integr Cancer Ther 13: 240-248, 2014.

35. Lin JM, Chen YQ, Wei LH, et al: Ursolic acid promotes colorectal cancer cell apoptosis and inhibits cell proliferation via modulation of multiple signaling pathways. Inter J Oncol 43: 1235-1243, 2013

36. Roehrborn CG, Nuckolls JG, Wei JT, et al: The benign prostatic hyperplasia registry and patient survey: study design, methods and patient baseline characteristics. BJU Int 100: 813-819, 2007.

37. Black L, Naslund MJ, Gilbert TD Jr, Davis EA and Ollendorf DA: An examination of treatment patterns and costs of care among patients with benign prostatic hyperplasia. Am J Manag Care 12: S99-S110, 2006

38. Roehrborn C, Boyle P, Nickel JC, Hoefner K and Andriole G: ARIA3001 ARIA3002 and ARIA3003 Study Investigators: Efficacy and safety of a dual inhibitor of 5-alpha-reductase types 1 and 2 (dutasteride) in men with benign prostatic hyperplasia. Urology 60: 434-441, 2002.

39. MacDonald Roderick and Wilt Timothy J: Alfuzosin for treatment of lower urinary tract symptoms compatible with benign prostatic hyperplasia: A systematic review of efficacy and adverse effects. Urology 66: 780-788, 2005

40. Youle RJ and Strasser A: The BCL-2 protein family: opposing activities that mediate cell death. Nat Rev Mol Cell Biol 9: 47-59, 2008.

41. Verma V, Sharma V, Singh V, et al: Labda-8(17),12,14-trien-19-oic acid contained in fruits of Cupressus sempervirens suppresses benign prostatic hyperplasia in rat and in vitro human models through inhibition of androgen and STAT-3 signaling. Phytother Res 28:1196-203, 2014. 